\title{
Ecosystem services for pollen beetle control in oilseed rape: ethical aspects of ecostacking-lost in translation?
}

\author{
Ingeborg Menzler-Hokkanen ${ }^{1}$
}

Published online: 18 September 2018

(c) The Author(s) 2018

In 2007, the European Plant Protection Agency EPPO organised a workshop on how to control the pollen beetle in Europe. 10 years later, a similar workshop was organised, demonstrating in its presentations the fast advancement of all predictions made 10 years ago. Although in 2007 during the EPPO workshop the increasing problems of pyrethroid resistance in the pollen beetle due to overuse by growers were presented, the control strategies for the major oilseed rape pests did not change in any way.

The present special issue contains contributions by European research groups, financed by different sources, proposing solutions to the problem. Characteristic to most contributions is that they are embedded in larger research projects, and the results obtained are of high importance. At the practical level, however, the reader is left with a "bag full of fragmented advice". In the eye of the practical person (the farmers), the "bag full of fragmented advice" seems unrelated, and not compatible with the economic and management reality on the farm. Concrete guidelines are needed in these complex situations for the practitioner, but are difficult to find. Solid ground on what to build management practices, and on what to build economically sound decisions, has to be provided.

Recently, the problems of pest management in conventional agriculture culminate in the decreasing availability of functioning chemical options, due to resistance evolution in target pests. Increasing costs of developing new chemical pesticides, and concerns about negative environmental impacts of the chemical pesticide approach, aggravate the problem. These include the suspected contribution to the declining numbers of pollinators, loss of biocontrol as ecosystem service, and an overall decline in numbers of flying

Ingeborg Menzler-Hokkanen

ingeborg.menzler-hokkanen@helsinki.fi

1 Department of Agricultural Sciences, University of Helsinki, Helsinki, Finland insects with consequent cascading effects throughout the food chain (e.g., insectivorous birds).

Abundant biocontrol knowledge and enthusiasm is available in Europe. Many outstanding cases where biocontrol has provided a solution can be presented - but none of these have been spectacular and with large enough impact to place biocontrol as the major option within mainstream agriculture. Overall economic and technical constraints have made it impossible so far.

Pest problems in European agriculture that have been solved with the help of biocontrol during the last 50 years include especially the greenhouse environment: greenhouse two-spotted spider mite, greenhouse whitefly, thrips, aphids, leaf-miners, etc. In the open field crops, Bacillus thuringiensis has successfully been used against a number of lepidopteran pests, and entomopathogenic nematodes in some cases, but overall the use of biocontrol in open field cultivations is minimal. Much more needs to be done in this respect.

\section{Biocontrol as an academic discipline: renaissance in European agriculture?}

Insect ecology, behaviour and management are at the centre in the study of ecosystem services that benefit agriculture and assure the sustainability of food and fibre production. The H2020 call SFS-28-2017 is an excellent example of picking up various ideas of biocontrol in order to solve urgent problems in European agriculture. In the following, some of the key elements of the call text SFS-28-2017 are cited to demonstrate the intention of returning to biocontrol as a venue for solutions.

SFS-28-2017 Functional biodiversity-productivity gains through functional biodiversity: effective interplay of crop pollinators and pest predators. 


\section{Specific challenge}

Biodiversity and various ecosystems serve agricultural production in many different ways, not all of which are well known. The smart use of these services can make agriculture more sustainable and reduce chemical inputs. The development of agricultural systems that maximise such services requires a "knowledge leap" based on advances in various areas of science, from new farming practices to modern technologies. The sustained delivery of these services by semi-natural habitats depends heavily on their botanical composition and spatial configuration and the soil characteristics. Beyond the field and farm level, cooperation between farmers and other actors is required at landscape level. There is a real need for a wide range of data to characterise and benchmark sustainable farming systems under various socio-economic and pedo-climatic conditions in Europe, and to find effective ways of encouraging farmers to adopt them.

\section{Scope}

Proposals will explore the functional role of biodiversity in the delivery of ecosystem services, in particular the spatial and temporal interactions between plants/animals as pollinators and natural enemies of pests. They will help to improve understanding of the factors and mechanisms that govern the delivery of such services, including agricultural management and landscape characteristics. Proposals will study and test approaches to enhancing the performance of the services by the targeted promotion of pollinators and natural enemies of pests through habitat provision and management. Cost effectiveness of these services will be compared with that of other agricultural practices (e.g., use of agrochemicals), including an evaluation of production stability and risk management for farmers and consumer demand. Work will examine synergies and trade-offs between pollination, the natural control of pests and other ecosystem services for agricultural production and environmental objectives. Prototypes of sustainable agro-ecology systems, including organic systems, agro-forestry and permaculture, will be developed from farm to landscape/territorial levels. Work will cover pastoral, arable and horticultural systems and potential forms of interaction and cooperation between these sectors at landscape level.

\section{Lost in translation?}

How has this resource possibility, provided by the Commission, translated into concrete research action by the scientific community in Europe? What went wrong in translating the call text into action?
To understand the situation, first a chronology of translation mistakes between a promising call text and academic reality has to be presented:

- Call SFS-28-2017 draft text available in October 2015, call opens in October 2016: maximum $10 \mathrm{M} €$ for a project to address the call "Functional biodiversity-productivity gains through functional biodiversity: effective interplay of crop pollinators and pest predators"

- The University of Helsinki (UH) team (Prof. Hokkanen, Dr. Menzler-Hokkanen) brainstormed the basic concepts of the EcoStack project, and invited consortium partners to participate ( 25 beneficiaries in the end)

- The proposal passed stage 1 , and the consortium was invited to submit a full proposal for stage 2

- Intense preparation continued, as there were several competing consortia for this topic

- UH team used own private funds to organise a "Project writing camp" with most WP leaders in July 2017 in Germany (Fig. 1)

- The UH administrators signed all commitment letters, and provided travel funding for Prof. Hokkanen to participate in a preparatory meeting for with 2-3 key partners, to finalise the application in August 2017 (Hokkanen and the EcoStack Consortium 2017)

- The UH team spent all its free time (vacations, weekends, etc) over the 2 years to prepare and write the proposal. All basic ideas to the proposal came from them, and about half of the text in the proposal was solely written by the UH team

- On 15 December 2017, the Commission informed that the proposal (EcoStack) had been selected for funding

- The UH team continued intense work on the project to finalise all Grant Agreement (GA) preparation requests with the Commission. Everything was achieved and fixed ahead of schedule. The GA was ready for signing in the second week of March 2018

- UH administrators had a deadline for signing the GA as the coordinating institution by 15 April 2018

- The UH research team had face-to-face discussions with UH administrators concerning the EcoStack project, and in particular its administration at UH. The UH team believed that an agreement had been reached on all questions

- On 11 April 2018, the Dean and the Head of Department still signalled to the UH team/project coordinator in an email that the Dean will sign the GA

- On 12 April the Dean sends an official letter to the Commission that UH does not take the EcoStack grant

- The UH team started, after discussions with the Commission Research Executive Agency, and based on the advice received, an immediate search for another EcoStack beneficiary to coordinate the project, and to accommodate 
the research and the researchers within the EcoStack consortium

- Finnish beneficiaries suitable for hosting EcoStack, however, declined (for example Turku University)

- The UH team had an excellent negotiation ongoing with the Swedish University of Agricultural Sciences, Uppsala, which was half-a-day away from deciding to take over UH's role

- The University of Naples (UNINA), Italy, interfered in this process by sending an email to all partners that UNINA is ready to coordinate the project; with that email SLU stopped negotiating with the UH team saying that they do not want to compete with Naples

- All beneficiaries agreed to the offer from Naples, in the fear that the whole project would be closed if they do not swiftly agree

- UNINA was assigned as the new coordinating institution by the Commission, and the new project coordinator (PC) quickly excluded the UH team from all further negotiations (because $\mathrm{UH}$ as an institution was not a partner any more)

- In the meanwhile, the UH team had negotiated perfect options to retain the research intended for Finland within the country, and the EcoStack beneficiary ProAgria had agreed (at the level of governing body) to take the socioeconomic work, and similarly the University of Eastern Finland (Kuopio) agreed to host the biological/ecological work (engaging prof. Hokkanen). However, the new PC ignored all that as an option.

- UH funds were distributed among remaining key beneficiaries, and the project proposal was modified so that all the contents remained (that the UH team had created and written), but the names of the UH team as WP leaders and Task leaders were replaced with other names, mostly from UNINA

- The UH team protested, and seeked advise from the IPRHelpdesk and the Ethics Helpdesk at the EU, because they feel that the IP what they had created and invented ("background-IP" to EcoStack) belongs to them, and could not be taken away from them in such a takeover. They also claim copyright to the proposal texts, which they solely had written, and which remained untouched but under other names in the Description of Work for EcoStack

- Despite two separate requests, the EU Ethics helpdesk did not comment on the situation at all. The IPR-helpdesk explained that this situation is unheard of, and juridically difficult — the only advice was to go to court and to seek justice

- In the meanwhile, all beneficiaries and the Commission have signed the Grant Agreement, and EcoStack starts on 10 September 2018-without the UH team, which acquired the grant

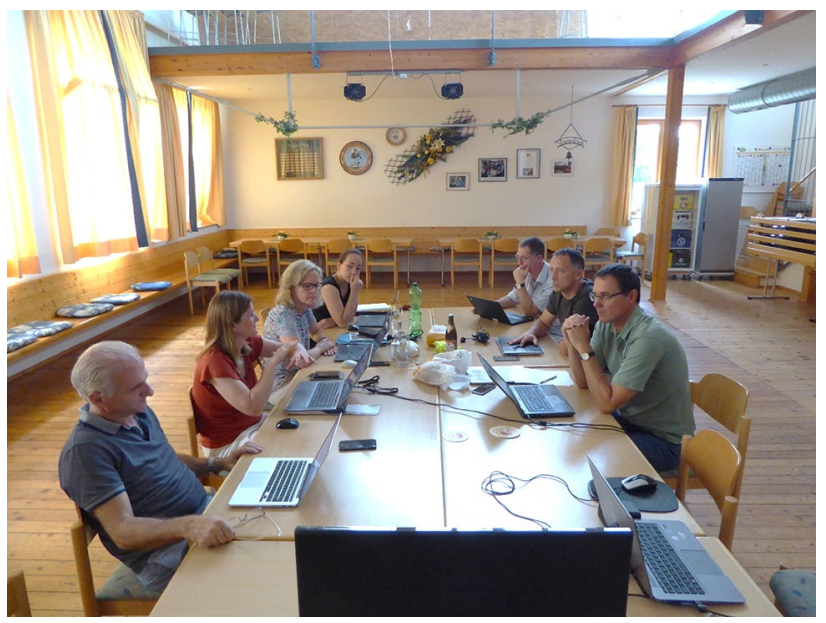

Fig. 1 An ethical and IPR disaster in the making: "EcoStack writing camp", hosted by the UH team privately in Bavaria in July 2017. Photo by Ingeborg Menzler-Hokkanen

\section{Research ethics and ownership of intellectual property rights of researchers at stake}

Following the events as listed above, the UH team requested that the European Commission examines the code of conduct including legality and ethical handling in the case of GA preparations for the $\mathrm{H} 2020$ research and innovation action number 773,554 "Stacking of ecosystem services: mechanisms and interactions for optimal crop protection, pollination enhancement, and productivity" (EcoStack). They suspected that their background IP had been violated, and was being misused in this process.

EcoStack is a research and innovation project in the area of agriculture, of importance to the whole European agrifood sector. It was the winning proposal addressing the call SFS-28-2017. The consortium consisted of 25 beneficiaries with a total budget of $9,963,866 €$. The project coordinator throughout the proposal preparation and writing stage, until the GA preparation stage was professor Heikki Hokkanen, UH, Finland.

Three days before the EC's deadline for signing the GA (15 April 2018), however, the coordinating institution, the University of Helsinki, decided not to accept the grant and withdrew from the EcoStack project. This decision was made by the Rector of the University, and was enforced topdown. Following this decision, the EcoStack GA preparation has progressed so that the resources allocated initially to $\mathrm{UH}$ have been divided among the key remaining beneficiaries, and the UH scientists including the previous PC have been excluded from participating in the project.

In the view of the UH research team, the continuation of the EcoStack project without the involvement of the key 
persons who initiated and created the proposal was legally and ethically questionable. Their position is that the background intellectual property (IP), on which the project is based, belongs to the UH team, and cannot be passed on to the remaining Ecostack consortium without the involvement of prof. Hokkanen and Dr. Menzler-Hokkanen.

The IP of the project coordinator and of the UH research team includes the overall concept of the EcoStack project, the name of the project, and large sections of the proposal, in which none of the other partners have had any input. For example, the whole section on project management structure and procedures (3.2) with its innovations (e.g., Project Progress Control and Planning, Management Tool, Monitoring and Evaluation System) was completely written by the original PC, and was not a standard text that is included in every EU-grant proposal. Similarly, the whole work-package on Policy Options and Dissemination with its innovations (e.g., Learning Platform, Resource Hub, Speak-Out Training) was completely written by Dr. Menzler-Hokkanen.

The view of the UH team is that their IP cannot be passed on to the remaining consortium and utilised without their involvement in the project. This is considered to violate the IP-rights, and not to be ethically or legally correct. The UH team had prepared and proposed a solution, where the $\mathrm{UH}$ team was fully integrated in the project as originally intended (but without involvement of UH), but that proposal was not seriously considered by the new PC, or by the REA. Therefore, the relevant bodies of the EC were requested to examine the situation and take action to rectify it.

\section{Plagiarism and copyright issues}

What is plagiarism and copyright? According to Webster's (Random House 1991), plagiarism is equated with kidnapping and defined as "the unauthorized use of the language and thoughts of another author and the representation of them as one's own". The Oxford English Dictionary (Simpson and Weiner 1989) defines plagiarism as the "wrongful appropriation or purloining, and publication as one's own, of the ideas, or the expression of the ideas (literary, artistic, musical, mechanical, etc.)". Plagiarism is thus the appropriation of another person's ideas, processes, results, or words without giving appropriate credit.

In addition to these definitions of plagiarism from dictionaries and encyclopedias, Ercegovac and Richardson (2004) include in the concept also cheating, academic dishonesty, academic misconduct, and copyright infringement. Plagiarism further involves questions of intellectual property, moral judgment, authorship, and literary ethics. Kibler (1993) defined academic dishonesty as "forms of cheating and plagiarism that involve students giving or receiving unauthorized assistance in an academic exercise or receiving credit for work that is not their own". Kibler also felt that the moral climate of the institution impacts the rate of cheating.

\section{Intellectual property in terms of unused original and creative ideas}

The central thinking behind the IPR is that the author or inventor must get his due recognition and reward, which will further encourage him to keep up the R\&D. Copyright protection has become a very important subject. 'Copyright' are the exclusive rights, which the law confers on authors (creator) to maintain their own terms and conditions for using their intellectual property. The oldest of all these exclusive rights is the right of the author of a book to print copies of it. This was the right conferred by the first copyright law, enacted in the U.K.

In the case of the Ecostack issue, the European IPR Helpdesk gave advice on 14.6.2018:

Yours is a highly unusual case, and indeed we have never encountered such a situation previously. For this reason, we will forward your query to the Research Enquiry Service of the European Commission (in an anonymised form) for their final assessment and will contact you regarding the outcome.

.

You should have in mind that intellectual property rights do not protect concepts or ideas, but only their original, physical expression (via copyright). In other words, no one can prevent them from being used by other participants. This may raise ethical issues, but it is not prohibited under intellectual property laws. ...

The sections of the bid that were redacted by your colleague and yourself are indeed protected by copyright. While this does not give you the right to stop the project participants from using the ideas expressed in it, it may mean that these parts of the bid cannot be used, copied and disseminated without the consent of the copyright owner (which will be either you and your colleague, or you employer depending on your employment contract). However, it is possible that implicit consent was given by submitting together the proposal thereby permitting the use, reproduction and dissemination of the copyrighted content in the context of the action. This is highly unclear to us, and we will therefore contact the Research Enquiry Service of the European Commission on this legal issue.

Please note that we are not the right platform to deal with questions regarding ethics in EU funded research 
projects. Rather you should contact the Ethics Helpdesk of the European Commission.

The European IPR Helpdesk further amended their advice on 2.7.2018:

Please find below the answer we received from the legal team of the European Commission after we passed on your query. As you can see, there does not seem to be a straightforward solution to the situation you have presented to us.

...

The situation you describe could be legally complex. Please note that the Enquiry Service does not validate individual cases, it only provides general guidance.

To conclude, given the many legal questions we would advise the researcher to seek specialised legal counsel.

\section{Official position by the Commission}

Assessment and official reply of the Commission was sent by Jerzy Plewa, The Director General of The European Commission Directorate-General for Agriculture and Rural Development, dated 23 July 2018:

I received your request to examine the code of conduct, including legality and ethical handling in the case of GA preparations for the H2020 project "EcoStack". The Commission and Research Executive Agency (REA) have taken note of your claims. Following the successful evaluation of the proposal, communicated to the consortium on 15 December 2017, REA implemented the subsequent steps for the grant preparation in accordance with the applicable Horizon 2020 rules. This includes the appointment of a new coordinator and redistribution of tasks following the withdrawal of the University of Helsinki.

$\cdots$

My services analysed your claims and have concluded that the elements you presented concern either your employment relation with the University of Helsinki, or the internal arrangements between the consortium members. In both situations, the Commission and REA are not able to intervene. If you are the owner of intellectual property related to the proposal and consider that the UH or another member of the consortium have violated your rights, you should settle the issue amica- bly or claim your rights before the competent national jurisdiction.

The advice that researchers need to seek justice in civil courts leaves individual researchers unprotected against predatory behaviour, and against being robbed of their research ideas and funds, as in the case of EcoStack. This reflects the inability of research administrators either at the home university, or at the European Commission, to follow and enforce the fundamental principles of research ethics and intellectual property rights. Given the financial possibilities of single researchers as compared with the UH or the EC, this advice is impractical.

The first step for researchers therefore to do is to talk about it, to raise the issue in public. In the EcoStack process, a lack of communication and transparency of practices by the new PC, and the quiet acceptance of extra funds by key beneficiaries, erodes trust in fair treatment and handling of the situation by all parties. Additionally the actual restructuring of the project management away from biocontrol specialists matching the call requirements, waters down the main message of the call, and the main impulses which the call text was intended to infuse into the present agricultural policy discussion. In my view, the message and intention have been lost in the translation of the call text into the current reality.

Open Access This article is distributed under the terms of the Creative Commons Attribution 4.0 International License (http://creativeco mmons.org/licenses/by/4.0/), which permits unrestricted use, distribution, and reproduction in any medium, provided you give appropriate credit to the original author(s) and the source, provide a link to the Creative Commons license, and indicate if changes were made.

\section{References}

Ercegovac Z, Richardson JV Jr (2004) Academic dishonesty, plagiarism included, in the digital age: a literature review. Coll Res Libraries 65:301-318. https://doi.org/10.5860/crl.65.4.301

Hokkanen HMT, The EcoStack Consortium (2017) Stacking of ecosystem services: mechanisms and interactions for optimal crop protection, pollination enhancement, and productivity. In: Horizon 2020. The European Commission, Brussels (Grant application Nr. 773554)

Kibler WL (1993) Academic dishonesty. NASPA J 30:252-257. https ://doi.org/10.1080/00220973.1993.11072323

Random House (1991) Webster's College Dictionary. Random House, New York

Simpson JA, Weiner ESC (1989) Oxford English Dictionary, 2nd edn. Clarendon Press, Oxford 